\title{
Narcolepsy Quality-of-Life Instrument with 21 Questions: A Translation and Validation Study in Chinese Pediatric Narcoleptics
}

\author{
Chenyang $\mathrm{Li}^{\prime}$ \\ Liang $\mathrm{Xie}^{2}$ \\ Shaomei Shang' \\ Xiaosong Dong ${ }^{3}$ \\ Xiaoling Wang ${ }^{4}$ \\ Long Zhao ${ }^{3}$ \\ Chi Zhang ${ }^{3}$ \\ Fang $\operatorname{Han}^{3}$
}

'Peking University School of Nursing, Beijing, People's Republic of China;

${ }^{2}$ Department of Neurology, The Second Affiliated Hospital of Nanchang

University, Nanchang, People's Republic

of China; ${ }^{3}$ Sleep Medicine Center,

Department of Respiratory and Critical

Care Medicine, Peking University People's Hospital, Beijing, People's Republic of

China; ${ }^{4}$ PKU-UPenn Sleep Center, Peking

University International Hospital, Beijing,

People's Republic of China
Correspondence: Fang Han Sleep Medicine Center, Department of Respiratory and Critical Care Medicine, Peking University People's Hospital, Beijing, 100044, People's Republic of China

Email hanfangI@hotmail.com
Objective: This study aimed to translate and validate the narcolepsy quality-of-life instrument with 21 questions (NARQoL-21) in Chinese pediatrics with narcolepsy.

Methods: NARQoL-21 was translated following the 10 steps of scale translation. The translated version was tested by exploratory factor analysis (EFA), confirmatory factor analysis (CFA), known-group validity, criterion validity, Cronbach's $\alpha$ and test-rest reliability.

Results: The Chinese version of NARQoL-21 consisted of two factors: (psychosocial factors and future outlook factor), including 20 items. EFA yielded 3 domains for psychosocial factors and 1 domain for future outlook factor. The Chinese version had a negative correlation with the overall Modified Epworth Sleepiness Scale $(r=-0.518, p<0.001)$ and meaningful difference in score between drug naïve and treated group $(p<0.05)$. The Cronbach's $\alpha$ coefficient was higher than 0.7 and intraclass correlation coefficient (ICC) ranged from 0.75 to 0.905 , indicating that it had good reliability.

Conclusion: The Chinese version of the NARQoL-21 is available and can be used to evaluate the health-related quality of life (HRQoL) of pediatric narcoleptics, despite that there is a shift in factors compared to the English version due to cultural differences. Future studies are recommended to further validate the scale in Chinese pediatrics with narcolepsy. Keywords: narcolepsy, pediatrics, quality of life, validation study

\section{Introduction}

Narcolepsy is a lifelong chronic neurological disorder affecting sleep. ${ }^{1}$ Typical symptoms include excessive daytime sleepiness (EDS), cataplexy, hypnagogic or hypnopompic hallucinations, sleep paralysis and disrupted nighttime sleep (DNS). ${ }^{2}$ The estimated clinical incidence of childhood narcolepsy in China was $0.04 \%{ }^{3}$ Narcolepsy typically presents during childhood, teenage years, or young adulthood and is generally lifelong after its onset. Unfortunately, it takes many years from onset to diagnosis. ${ }^{4}$

Pediatric patients with narcolepsy had more comorbidities, such as respiratory and mental health comorbidities, as well as higher health care utilization and costs than patients without narcolepsy. ${ }^{5}$ The psychosocial consequences of this disorder were particularly severe with high rates of academic failure, psychological disorder and poor health-related quality of life (HRQoL) extending into adulthood. ${ }^{6}$ The persistence of narcolepsy symptoms, the burden of chronic management and consequent comorbidities have been proved to compromise HRQoL of narcoleptics. ${ }^{7}$ 
A range of altered neuropsychological processes and other psychological aspects adversely affected the patients' HRQoL and achievements. ${ }^{8}$ Narcolepsy had adverse effects on narcoleptics' HRQoL in a homogeneous way across countries, independently from cultural and geographic provenience. ${ }^{8}$ Children and adolescents with narcolepsy were at high risk of poor HRQoL and psychosocial symptoms such as depression, so a more thorough assessment and management of psychological health was recommended. ${ }^{9}$

The large number of publications on HRQoL of pediatric narcoleptics reflected the increasing awareness and the substantial role gaining in clinical practice and research. HRQoL was one of important endpoints when considering the efficacy of medical intervention, and it might be useful to understand the pediatric perspective in any assessment of treatment outcome in either routine audit work or clinical trials. ${ }^{10}$ Despite the increasing interest in narcoleptic HRQoL, as well as its prevalence and clinical significance, there was a lack of specific and widespread instruments to evaluate HRQoL.

Numerous instruments were used to assess the pediatric HRQoL, such as the Pediatric Quality of Life Inventory (PedsQL) scale, ${ }^{11,12}$ Vécu et Santé Perçue de l'Adolescent (VSP-A), ${ }^{13}$ the Child Behavior Checklist (CBCL), ${ }^{14,15}$ the Strengths and Difficulties Questionnaire (SDQ) ${ }^{16}$ and the Child Health Questionnaire (CHQ). ${ }^{17}$ However, the above questionnaires lacked specificity for pediatric narcoleptics. A well-known advantage of a disease-specific measure was a higher sensitivity for detection and quantification of specific symptoms.

To overcome the above limitation, Chaplin et $\mathrm{al}^{18}$ developed both Swedish and English version of Narcolepsy qualityof-life instrument with 21 questions (NARQoL-21) for children and adolescents with narcolepsy in 2017. Chaplin et al ${ }^{18}$ stated that NARQoL-21 had good validity and reliability.

Moreover, NARQoL-21 was also proved its superiority of difference detection in HRQoL between children with and without psychiatric comorbidity, as well as its advantages both in clinical and research applications in the following study published in $2019 .{ }^{19}$ As far as we know, there was no Chinese version of NARQoL-21; therefore, our aim in this study was to translate and validate the Chinese version of NARQoL-21.

\section{Materials and Methods}

\section{NARQoL-2I Translation}

NARQoL-21 was translated following the 10 steps of scale translation. ${ }^{20}$ After Dr. Chaplin authorized us to use the instrument, two native Chinese speakers conducted forward translation independently. To estimate the accuracy and fluency of translated NARQoL-21 and discuss any inconsistencies in translations, study panel reviewed and compared the two distinct Chinese versions of NARQoL-21 and finally determined the Chinese version. A native English translator who had no access to the original English version of NARQoL-21 performed back translation. This new back translation version was compared to the original version.

Study panel reviewed and evaluated all versions of NARQoL-21 to estimate the compatibility between them. Then, we did pre-testing by surveying 10 patients using NARQoL-21, and the feedback from them indicated all questions were clear and understandable. As an outcome of this, the final Chinese version of NARQoL-21 was established and approved.

\section{Sample and Participants}

Since NARQoL-21 consisted of 21 items and the sample size for methodological research was recommended to be 5 times more than the items in the scale, ${ }^{21}$ we first recruited a convenience sample of 105 pediatric narcoleptics to conduct exploratory factor analysis (EFA). Moreover, we obtained more 96 data to perform confirmatory factor analysis (CFA) using 201 samples. All pediatric narcoleptics were from the sleep center of Peking University People's Hospital in Beijing, China. Inclusion criteria were as follows: (a) all of them underwent on nocturnal polysomnography (nPSG), multiple sleep latency test (MSLT), genetic marker of HLA-DQB1*06 :02 and/or chemical measurement of low levels of hypocretin in cerebrospinal fluid (CSF) and were diagnosed with narcolepsy according to ICSD- $3,^{2}$ (b) aged from 8 to 18 years old, (c) able to read Chinese, and (d) will to participate in this study. Exclusion criteria included combined with other sleep disorders or mental illness or poor mental condition. All patients signed the informed consent after obtaining consent and the consent of their parents or legal guardians were provided written informed consent, and this study was conducted in accordance with the Declaration of Helsinki. Prior to applying research, this study was approved by the ethics committees of Peking University People's Hospital.

\section{Data Collection}

Patients answered the NARQoL-21, Modified Epworth Sleepiness Scale, and questions on Sociodemographic characteristics, ie age, gender, weight, height, onset age, 
disease duration. Moreover, clinical presentation and results of nPSG, MSLT, HLA-DQB1*06:02 and/or hypocretin in CSF were also obtained.

\section{Instruments}

\section{Chinese Version of NARQoL}

NARQoL-21 was a self-reported narcolepsy-specific HRQoL questionnaire for children and adolescents. ${ }^{18}$ The item list was developed from the expressed views of children and adolescents with narcolepsy, aging from 8 to 18 years. NARQoL-21 included two factors, five domains, and 21 items. The first was Psychosocial factor with 15 items assigning to three domains: Emotional reaction, Social confidence and School/Concentration. The second was Future outlook factor with 6 items assigning to two domains: Expectations and Limitations. Each item was answered by the patient on a five-point Likert scale from completely untrue to completely true. The summated rating method was used for each domain and, for ease of interpretation, the raw scores were transformed to a 0 to 100 scale in which higher scores indicated better narcolepsy-specific HRQoL.

\section{Modified Epworth Sleepiness Scale}

Modified Epworth Sleepiness Scale composed of eight questions, assessing the sleepiness of the subject in reallife situations. $^{22}$ The modified version removed the reference to alcohol from item 7 to "sitting quietly by yourself after lunch". Item 8 was replaced by "as a passenger for a few minutes" substituted for "in a car". Each question was scored from 0 to 3 (no chance to high chance of dozing), with a maximum score of 24. Total scores above 10 were regarded as EDS and indicated the presence of underlying sleep disorders. The questionnaire was translated into Chinese and had been proved to have good validation and reliability. $^{23}$

\section{Data Analysis}

A descriptive analysis was first performed on the collected data to gain an understanding of the demographic and clinical characteristics of recruited participants. Frequency, percentage, and Fisher's exact test were used to express the categorical variables, while mean \pm standard deviation (SD) and Student's $t$-test were applied to describe continuous variables.

The final Chinese version NARQoL-21 subscales were tested for construct validity, including EFA, CFA, known group validity and criterion validity. Prior to EFA, the KaiserMeyer-Olkin (KMO) and Bartlett's sphericity test were applied to calculate the adequacy of sampling. In the EFA, both principal components and principal axis factor analyses with Promax rotation were performed. Factors with a factor loading $>0.40$ were extracted. $^{21}$ For the item reduction, item was considered removed if they failed to load with sufficient strength $(<0.4)$ on any factor or had high cross-loading $(>0.3){ }^{21}$ CFA was also used to further validate the preset model of the scale. The chi-square to degree of freedom ratio $\left(\chi^{2} / \mathrm{df}\right)$, root mean square error of approximation (RMSEA), the goodness-of-fit index (GFI), Tucker Lewis Index (TLI) and comparative fit index (CFI) were used to confirm the goodness of fit. Known-group validity was determined using the paired $t$-test. Criterion validity was tested with Pearson's correlation analysis. If the respondents answered with a high or low score of more than $15 \%$, indicating that there were floor and ceiling effects.

Reliability was assessed by the Cronbach's $\alpha$ and testrest reliability. For the Cronbach's $\alpha$, a value of 0.7 or higher indicated acceptable reliability. An intraclass correlation coefficient (ICC) above 0.70 was considered to have satisfactory test-rest reliability. ${ }^{24}$

SPSS 22.0 and AMOS 21.0 were used for data analysis. The significance level was set at $\mathrm{p}$-value $<0.05$.

\section{Results}

\section{Sociodemographic Characteristics}

A total of 201 patients (aged 8 to 18 years) with narcolepsy completed the Chinese version of NARQoL-21 once. Among them, 19 patients complete the validation study survey twice in an interval of 2 weeks. The average age of participants was $13.32 \pm 2.85$ years. The onset age and disease duration had $8.49 \pm 3.29$ years and $4.38 \pm 3.21$ years, respectively. $65.2 \%(\mathrm{~N}=131)$ were boys, 188 pediatrics had positive HLA-DQB1*06:02, and 78.4 (40/51) had lower hypocretin in CSF less than $110 \mathrm{pg} / \mathrm{mL}$. The NARQoL-21 total, Psychosocial factor and Future outlook factor mean transformed score were $47.48 \pm 16.05,44.84$ \pm 16.68 and $54.01 \pm 18.11$, respectively. Table 1 presented the characteristics of recruited sample. Figure 1 indicated that there were no patients answered with a high or low score of more than $15 \%$, showing the floor and ceiling results were acceptable.

\section{Validity of the NARQoL-2I EFA and CFA Results}

Internal structure validity was verified by applying the EFA using 21 items. The KMO and Bartlett test confirmed 
Table I Sociodemographic and Clinical Characteristics of Patients

\begin{tabular}{|c|c|c|c|}
\hline \multirow[t]{2}{*}{ Variables } & \multicolumn{2}{|c|}{ Mean \pm SD or $\%$} & \multirow[t]{2}{*}{$P$ value } \\
\hline & $\begin{array}{l}\text { Narcolepsy with Cataplexy } \\
(\mathrm{N}=184)\end{array}$ & $\begin{array}{l}\text { Narcolepsy Without } \\
\text { Cataplexy }(\mathrm{N}=\mid 7)\end{array}$ & \\
\hline Age (years) & $13.3 \pm 2.9$ & $13.9 \pm 2.2$ & 0.347 \\
\hline Gender (M \%) & $67.4(124 / 184)$ & $41.2(7 / / 7)$ & 0.03 \\
\hline $\begin{array}{l}\text { Treated (\%) } \\
\text { Both stimulant and anticataplectic drug (\%) } \\
\text { Both modafinil andmethylphenidate (\%) } \\
\text { Methylphenidate only (\%) } \\
\text { Venlafaxine only (\%) } \\
\text { Clomipramine only (\%) }\end{array}$ & $\begin{array}{l}33.2(6 \mathrm{I} / \mathrm{l} 84) \\
45.9(28 / 6 \mathrm{I}) \\
1.6(1 / 61) \\
37.7(23 / 61) \\
8.2(5 / 61) \\
6.6(4 / 61)\end{array}$ & $\begin{array}{l}23.5(4 / 17) \\
- \\
25(1 / 4) \\
50(2 / 4) \\
- \\
25(1 / 4)\end{array}$ & 0.417 \\
\hline BMI & $24.8 \pm 5.4$ & $25.0 \pm 6.1$ & 0.898 \\
\hline Onset age (years) & $8.3 \pm 3.2$ & $11.4 \pm 2.3$ & $<0.01$ \\
\hline Disease duration (years) & $4.6 \pm 3.2$ & $2.1 \pm 1.9$ & 0.002 \\
\hline $\begin{array}{l}\text { Lab testing } \\
\text { \% HLA-DQBI*06:02 } \\
\text { \%Hcrt- I<I I0 pg/mL }\end{array}$ & $\begin{array}{l}100(184 / 184) \\
100(40 / 40)\end{array}$ & $\begin{array}{l}23.5(4 / 17) \\
0(0 / 11)\end{array}$ & \\
\hline $\begin{array}{l}\text { nPSG testing } \\
\text { Sleep efficiency (\%) } \\
\text { Total sleep time (min) } \\
\text { AHI (/h) }\end{array}$ & $\begin{array}{l}85.9 \pm 13.6 \\
464.1 \pm 70.4 \\
2.1 \pm 3.1\end{array}$ & $\begin{array}{l}93.7 \pm 4.5 \\
496.8 \pm 71.0 \\
3.4 \pm 4.6\end{array}$ & $\begin{array}{l}0.049 \\
0.187\end{array}$ \\
\hline $\begin{array}{l}\text { MSLT } \\
\text { Sleep latency }(\mathrm{min}) \\
\text { No. SOREMPs }\end{array}$ & $\begin{array}{l}2.0 \pm 2.2 \\
4.1 \pm 1.0\end{array}$ & $\begin{array}{l}4.4 \pm 2.6 \\
3.5 \pm 1.1\end{array}$ & $\begin{array}{l}0.001 \\
0.051\end{array}$ \\
\hline
\end{tabular}

Abbreviations: nPSG, nocturnal polysomnography; AHI, apnea hypopnea index; MSLT, multiple sleep latency test; No. SOREMPs, numbers of sleep onset rapid eye movement periods; HLA, human leukocyte antigen; HLA-DQBI*06:02, HLA-DQBI*06:02 is positive.

that it was fit for applying this technique to this sample $(\mathrm{KMO}=0.827$, Bartlett's Test of Sphericity $=688.611$, $\mathrm{p}<0.001)$. Both principal components and principal axis factor analyses with Promax rotation were undertaken. Firstly, principal axis factor analysis was used to explore the domain of Psychosocial factor. As shown in Table 2 (Suppl Table 1), although the factor loading of item 18 (I stay awake when I watch TV) was less than 0.4 on all three domains, it was related to the sleepiness symptom and ability to stay alert, which was the core symptom of narcolepsy. Therefore, this item was kept due to its important clinical significance. Thus, in this step, EFA analysis defined three components of the Psychosocial items (Emotional, School/Concentration, and Social confidence) considering the method of the eigenvalues $>1$ with $57.92 \%$ explained variance. Secondly, to further determine the stability of the structure of Psychosocial factor, we used principal component analysis to perform EFA again, and got the similar results (Table 2).

However, in the same way, the Future outlook factor, item 14 (I will not travel as much as others) was removed because factor loading was less than 0.3 on factors. Then, as shown in Table 3 (Suppl Table 1), the EFA result indicated that one factor solution gave the best description using both principal axis factor analysis and principal component analysis, with $52.987 \%$ explained variance $(\mathrm{KMO}=0.754$, Bartlett's Test of Sphericity $=146.702, \mathrm{p}<0.001$ ). We also verified the structure of Future outlook factor with 201 samples, and the results were consistent (Suppl Table 2).

The CFA was also performed on the NARQoL-21 questions using AMOS 21.0. Figure 2 showed the goodness of fit of the Psychosocial factor model: $\chi^{2}=163.984, \mathrm{P}<0.001, \chi^{2}$ । $\mathrm{df}=1.952, \quad \mathrm{RMSEA}=0.07, \quad$ GFI $=0.907, \quad \mathrm{TLI}=0.902$, $\mathrm{CFI}=0.921$, indicating an acceptable model fit. ${ }^{25}$ 


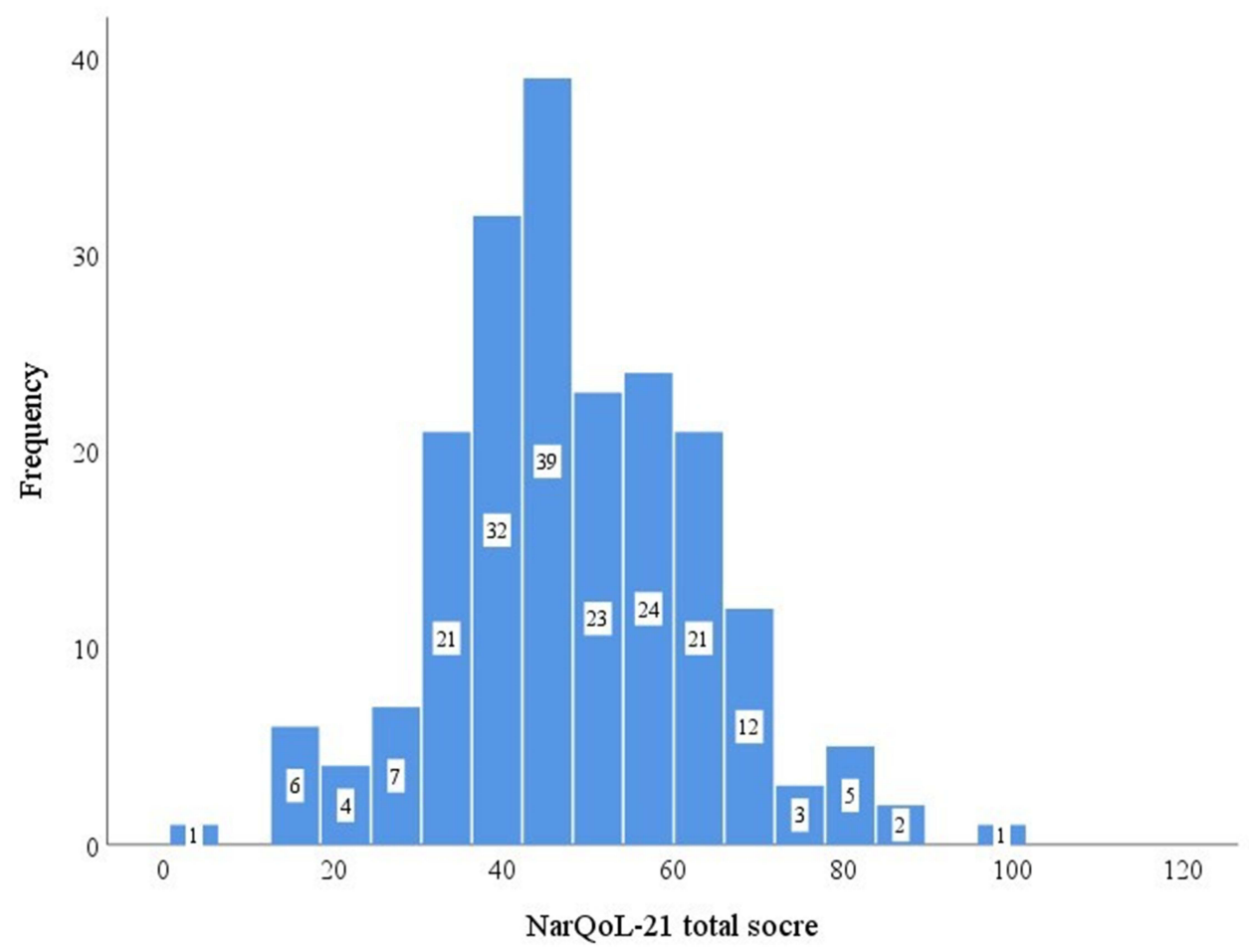

Figure I Floor and ceiling results.

\section{Criterion Validity}

To verify criterion validity, correlations between NARQoL-21 and Modified Epworth Sleepiness Scale were analyzed (Figure 3). The results showed that the overall NARQoL-21 had a negative correlation with scores of Modified Epworth Sleepiness Scale $(r=-0.518, p<0.001)$.

\section{Known-Group Validity}

Known-group validity measured an instrument's ability to distinguish among distinct groups. ${ }^{26}$ Known group validity examined whether the NARQoL-21 was able to show meaningful differences in score between respondents (drug naïve and treated groups) who differed by self-

Table 2 Psychosocial Factor Structure of the Chinese Version of NARQoL-2I ( $N=105)$

\begin{tabular}{|l|c|c|c|c|c|c|}
\hline \multirow{2}{*}{ Items } & \multicolumn{3}{|c|}{ Extraction Method I } & \multicolumn{3}{c|}{ Extraction Method 2 } \\
\cline { 2 - 6 } & Domain I & Domain 2 & Domain 3 & Domain I & Domain 2 & Domain 3 \\
\hline Ability to follow lessons & -0.026 & 0.715 & -0.095 & -0.002 & 0.799 & -0.131 \\
Feeling lazy & $0.4 I I$ & 0.005 & $0.08 I$ & 0.602 & -0.069 & 0.025 \\
Ability to concentrate & 0.205 & 0.507 & -0.075 & 0.311 & 0.580 & -0.179 \\
Sadness & 0.612 & -0.124 & 0.255 & 0.607 & -0.134 & 0.368 \\
Alertness & 0.019 & 0.607 & 0.126 & 0.089 & 0.644 & 0.087 \\
Anger & 0.140 & -0.032 & 0.811 & 0.181 & -0.111 & 0.841 \\
Not giving up easily & 0.441 & 0.194 & 0.032 & 0.582 & 0.194 & -0.023 \\
Alertness in school & 0.170 & 0.655 & -0.073 & 0.144 & 0.727 & -0.020 \\
Feeling alone & 0.765 & 0.030 & 0.016 & 0.611 & 0.129 & 0.215 \\
Getting on with others & 0.723 & -0.002 & -0.028 & 0.645 & 0.072 & 0.112 \\
Anxiety & 0.652 & 0.055 & 0.197 & 0.532 & 0.112 & 0.383 \\
Feeling confident & 0.850 & -0.037 & -0.157 & 0.825 & 0.056 & -0.110 \\
Staying awake when watching TV & 0.197 & 0.320 & -0.064 & 0.332 & 0.404 & -0.223 \\
Irritability & -0.037 & 0.046 & 0.934 & 0.041 & -0.056 & 0.912 \\
Staying awake on the bus & $-0.28 I$ & 0.562 & 0.220 & -0.490 & 0.684 & 0.418 \\
\hline
\end{tabular}

Notes: NARQoL-2I: health-related quality-of-life instrument for young people with narcolepsy; Domain I: Social confidence; Domain 2: School/Concentration; Domain 3: Emotional reaction; Extraction Method I: Principal Axis Factoring, Rotation Method: Promax with Kaiser Normalization; Extraction Method 2: Principal Component Analysis, Rotation Method: Promax with Kaiser Normalization; Suppl Table I shows the details of each item. 
Table 3 Future Look Factor Structure of the Chinese Version of NARQoL-2I $(\mathrm{N}=105)$

\begin{tabular}{|l|c|c|}
\hline \multirow{2}{*}{ Items } & Extraction Method I & Extraction Method 2 \\
\cline { 2 - 3 } & Domain I & Domain I \\
\hline Problems in the future & 0.537 & 0.661 \\
Driving license & 0.550 & 0.668 \\
Hopeful future & 0.840 & 0.844 \\
Possibilities & 0.786 & 0.818 \\
After leaving school & 0.483 & 0.619 \\
\hline
\end{tabular}

Notes: Domain I: Future outlook; Extraction Method I: Principal Axis Factoring; Extraction Method 2: Principal Component Analysis; Suppl Table I shows the details of each item.

perceived HRQoL. Figure 4 showed that in the drug naïve patients, the NARQoL-21 and domains total score increased significantly after taking medicine.

\section{Reliability of the NARQoL-2 I}

Cronbach's $\alpha$ was calculated to evaluate the internal consistency. The internal consistency of the NARQoL21 showed a Cronbach's $\alpha$ coefficient for NARQoL-21 (20 items), Psychosocial domains (14 items), Emotional reaction (2 items), School/Concentration (6 items), Social confidence (7 items) and Future outlook (5 items) were all above 0.7 , which indicated high degree of internal consistency and homogeneity (Table 4).

As shown in Table 4, test-retest ICC of NARQoL21 and domain scores were from 0.75 to 0.905 $(\mathrm{p}<0.01)$, indicating a strong relationship between total NARQoL-21 scores recorded two weeks after the initial interview.

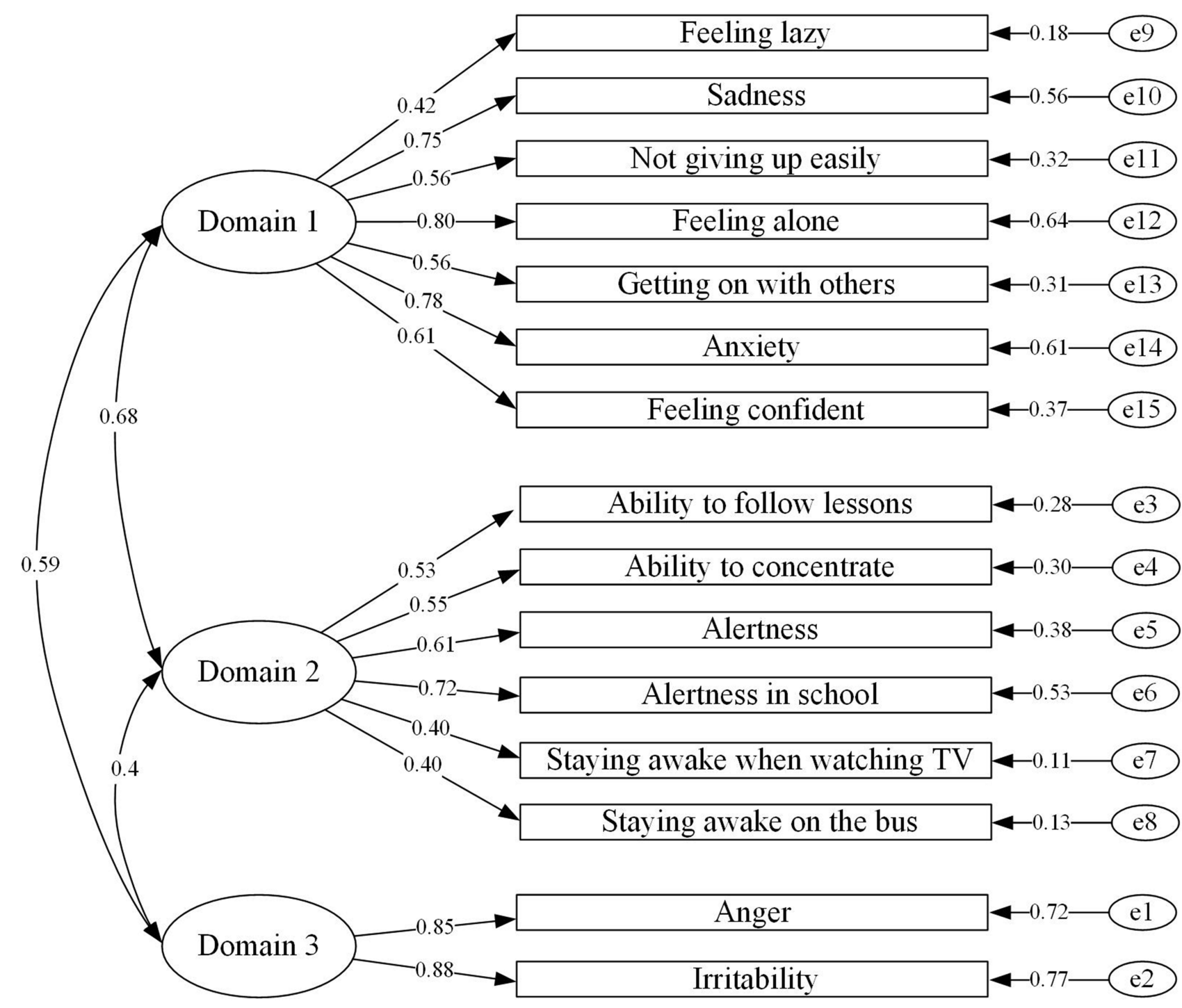

Figure 2 Confirmatory factor analysis result of Psychosocial factor. Domain I: Social confidence; Domain 2: School/Concentration; Domain 3: Emotional reaction. 


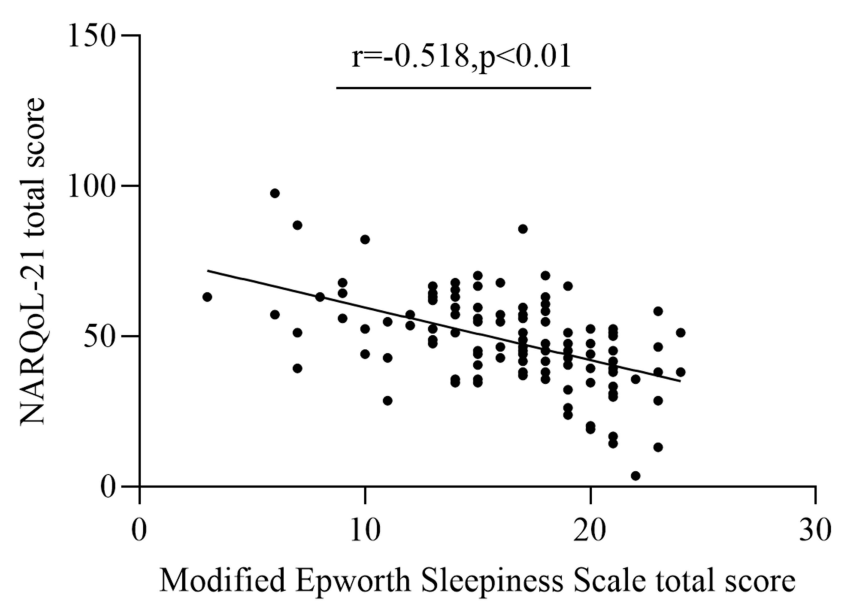

Figure 3 Results of criterion validity.

\section{The Feasibility of the Clinical Cut-off of NARQoL-2I}

According to the study, ${ }^{18}$ the NARQoL-21 score of lower than 42 could identify individuals with suboptimal $\mathrm{HrQoL}$ with a sensitivity of $84 \%$ and specificity of $92 \%$. When we divided our samples into optimal HRQoL group and suboptimal HRQoL group on a cutoff value of 42, the patients in the suboptimal HRQoL group had higher Modified Epworth Sleepiness Scale total scores $(18.74 \pm 3.47$ vs $15.25 \pm 4.49, \mathrm{t}=4.63, \mathrm{p}<0.01$ ) (Figure 5).

\section{Discussion}

Clinical evidence showed that HRQoL measurement was an indispensable outcome of patients' clinical improvement ${ }^{27}$ and could contribute to evaluating the efficacy of treatment in chronic illness. ${ }^{10}$ It was essential to have specific tools available to evaluate HRQoL of pediatrics with narcolepsy. To the best of our knowledge, this was the first study to examine the validity and reliability of Chinese version of NARQoL-21. The results suggested that the Chinese version of NARQoL-21 consisted two factors (Psychosocial factors included 15 items and Future outlook factor included 5 items), including 20 items. Psychosocial factor consisted of three domains: Emotional reaction (2 items), School/Concentration (6 items) and Social confidence ( 7 items). The Chinese version of NARQoL-21 was specific for pediatric narcoleptics and had good validity and reliability, allowing to evaluate the HRQoL of pediatrics with narcolepsy. The availability of Chinese version of NARQoL-21 provided accurate and safe tool for Chinese pediatric narcoleptics' HRQoL evaluation. Moreover, Chinese version of NARQoL-21 was a specific and self-reported questionnaire, the patient could be an active participant in the assessment/quantification of the HRQOL.

However, there was still a difference from the English version of NARQoL-21. Compared with the original version, item 14 was removed due to the low factor loading. Item 14 referred traveling, which might also be inconsistent with Chinese context and it seemed reasonable to delete this item. Item 18 was retained despite having a factor load of less than 0.4 when analyzed by principal axis factor analysis. One of the reasonable explanations
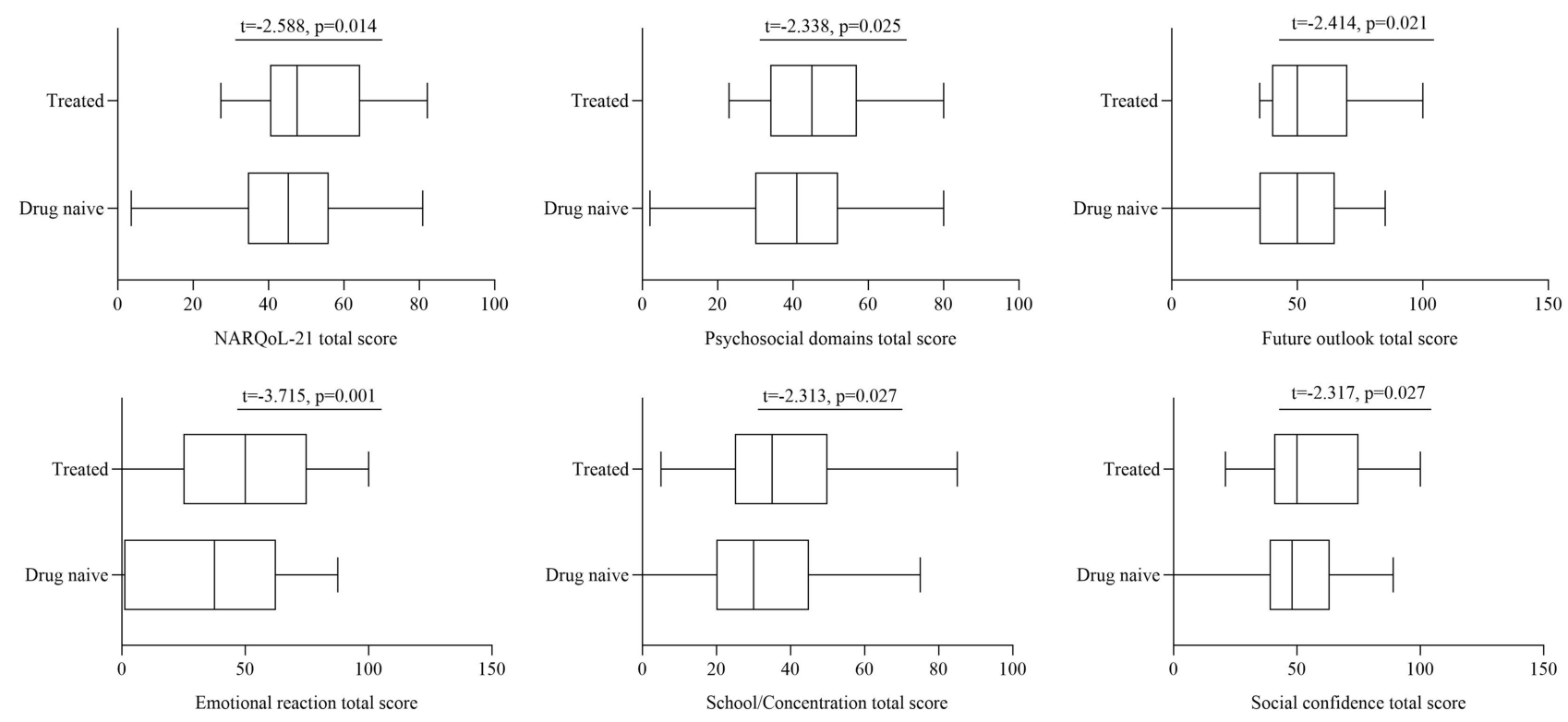

Figure 4 Results of known-group validity. 
Table 4 Reliability of the NARQoL-2I

\begin{tabular}{|c|c|c|}
\hline & $\begin{array}{c}\text { Cronbach's } \alpha \\
\text { Coefficient }\end{array}$ & ICC \\
\hline NARQoL-2I (20 items) & 0.889 & $0.853^{* *}$ \\
Psychosocial domains (15 items) & 0.858 & $0.830^{* *}$ \\
Emotional reaction (2 items) & 0.857 & $0.750^{* *}$ \\
School/Concentration (6 items) & 0.730 & $0.835^{* *}$ \\
Social confidence (7 items) & 0.831 & $0.905^{* *}$ \\
Future outlook (5 items) & 0.750 & $0.863^{* *}$ \\
\hline
\end{tabular}

Note: $* * p<0.01$.

Abbreviation: ICC, intraclass correlation coefficient.

was that EDS, one of the core symptoms of narcolepsy, generally caused by monotonous circumstances or sedentary activities like watching television. ${ }^{2,28}$ Item 18 involved the sleepiness when watching TV, which seemed to be necessary not only for diagnosis, but also for evaluation. Therefore, it might make sense to keep item 18.

Moreover, there was also a shift in domains. Regarding the Psychosocial factor, EFA using principal axis factor analyses/principal component analysis with Promax rotation defined three components among 15 remaining items. Same as the original version, these three domains were Emotional, School/Concentration and Social confidence. However, item 4 (I feel sad or low), item 12 (I feel lonely) and item 15 (I get anxious)

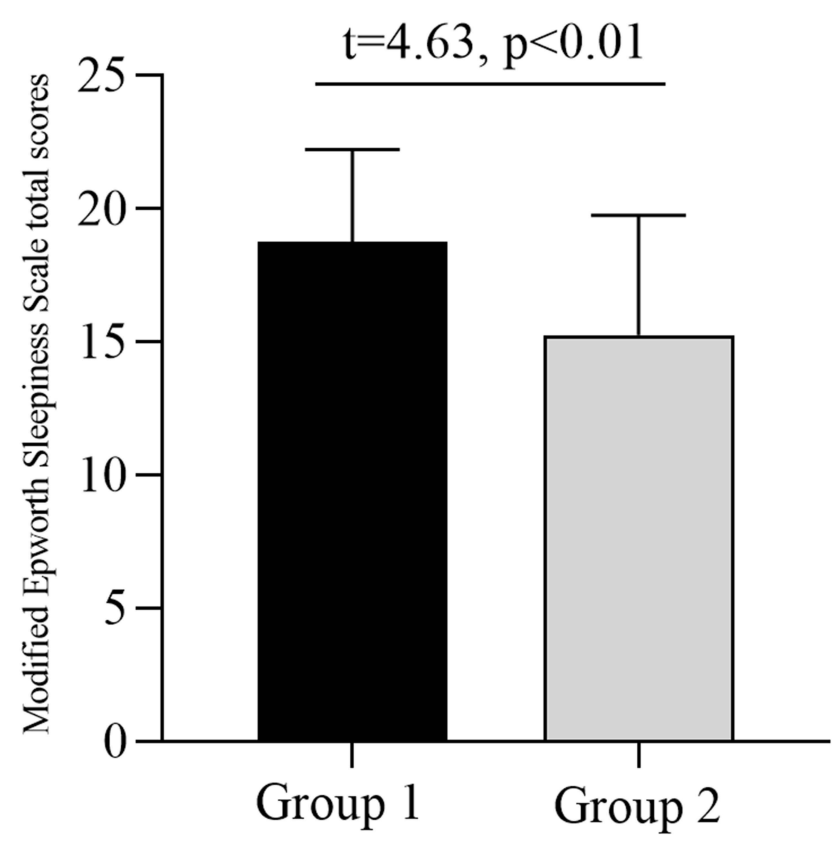

Figure 5 Modified Epworth Sleepiness Scale total scores in different groups. Group I: Suboptimal HRQoL group; Group 2: Optimal HRQoL group. Abbreviation: HRQoL, health-related quality of life. were assigned to the Social confidence domain. Selfperception such as anxiety appeared to be related to the unpredictable nature of narcolepsy symptoms or avoidance of certain situations due to narcolepsy symptoms. Indeed, narcoleptics especially those with cataplexy avoided related to having cataplexy in social situations, which might comprise the social functions. ${ }^{29}$ It was also reported that functional limitations might affect the ability to socialize with friends or the extent to which they spend time and energy making or maintaining friendships. ${ }^{29}$ Based on the above, this shift was acceptable with reasonable clinical significance and good validity. Moreover, the CFA also indicated the Psychosocial factor model had a goodness of fit.

So, based on the above, we could deduce that in the Chinese version, Emotional, School/Concentration and Social confidence domain included 2 items, 6 items and 7 items, respectively. Contrast to the Future outlook factor of original version, we deleted item 14 , because it had lower factor loading and was not suitable for our national conditions, EFA yielded only one domain. All the five items were related to the Future outlook.

Despite of the shifts, the Chinese version of NARQoL-21 also showed good criterion validity, Known-group validity, internal consistency, and test-retest reliability, which were in line with the original version. ${ }^{18}$ Moreover, we found that the Chinese version of NARQoL-21 was useful to distinguish the levels of HRQoL between pre- and post-treated patients, as well as to identify the suboptimal or optimal HRQoL among pediatric narcoleptics via the cutoff value of 42 .

There were some limitations in this study. Firstly, the recruited samples were from a single hospital, which could result in some bias regarding demographic differences despite the fact that our hospital, as a tertiary center, received a wide variety of narcoleptics. Secondly, although the cut-off value of 42 reported in the study was preliminary validated, we failed to identified the cut-off value in Chinese patients due to the limited samples and instruments. In order to obviate that, we plan to continue recruiting more samples as well as pre-post treated samples in multicenter, which allowed us to further validate the Chinese version of NARQoL-21.

\section{Conclusion}

HRQoL is an indispensable outcome of patients' clinical improvement. Our study indicates the availability of the Chinese version of the NARQoL-21. In addition, there is a shift in factors compared to the English version due to 
cultural differences, and future studies are recommended to further validate the practicality and effectiveness of NARQoL-21 in Chinese pediatrics with narcolepsy.

\section{Acknowledgments}

We thank Prof. Chaplin for authorizing us to use the scale and all patients for taking part in this study.

\section{Funding}

This research was supported by the National Natural Science Foundation of China (NSFC) (No. 82020108001 and No. 81420108002).

\section{Disclosure}

The authors have no conflicts of interest.

\section{References}

1. Nishino S, Mignot E. Narcolepsy and cataplexy. Handb Clin Neurol. 2011;99:783-814. doi:10.1016/B978-0-444-52007-4.00007-2

2. Sateia MJ. International classification of sleep disorders-third edition: highlights and modifications. Chest. 2014;146(5):1387-1394. doi:10.1378/chest.14-0970

3. Han F, Chen E, Wei H, et al. Childhood narcolepsy in North China. Sleep. 2001;24(3):321-324. doi:10.1093/sleep/24.3.321

4. Maski K, Steinhart E, Williams D, et al. Listening to the patient voice in narcolepsy: diagnostic delay, disease burden, and treatment efficacy. J Clin Sleep Med. 2017;13(3):419-425. doi:10.5664/ jcsm.6494

5. Carls G, Reddy SR, Broder MS, et al. Burden of disease in pediatric narcolepsy: a claims-based analysis of health care utilization, costs, and comorbidities. Sleep Med. 2020;66:110-118. doi:10.1016/j. sleep.2019.08.008

6. Thorpy MJ, Hiller G. The medical and economic burden of narcolepsy: implications for managed care. Am Health Drug Benefits. 2017;10(5):233-241.

7. Raggi A, Plazzi G, Ferri R. Health-related quality of life in patients with narcolepsy: a review of the literature. J Nerv Ment Dis. 2019;207(2):84-99. doi:10.1097/NMD.0000000000000918

8. Ingravallo F, Gnucci V, Pizza F, et al. The burden of narcolepsy with cataplexy: how disease history and clinical features influence socio-economic outcomes. Sleep Med. 2012;13(10):1293-1300. doi:10.1016/j.sleep.2012.08.002

9. Inocente $\mathrm{CO}$, Gustin MP, Lavault $\mathrm{S}$, et al. Quality of life in children with narcolepsy. CNS Neurosci Ther. 2014;20(8):763-771. doi:10.1111/cns.12291

10. Eiser C, Morse R. A review of measures of quality of life for children with chronic illness. Arch Dis Child. 2001;84(3):205-211. doi:10.1136/adc.84.3.205

11. Varni JW, Seid M, Rode CA. The PedsQL: measurement model for the pediatric quality of life inventory. Med Care. 1999;37 (2):126-139. doi:10.1097/00005650-199902000-00003

12. Varni JW, Burwinkle TM, Seid M, Skarr D. The PedsQL 4.0 as a pediatric population health measure: feasibility, reliability, and validity. Ambulatory Pediatr. 2003;3(6):329-341. doi:10.1367/15394409(2003)003<0329:TPAAPP $>2.0 . \mathrm{CO} ; 2$
13. Simeoni MC, Auquier P, Antoniotti S, Sapin C, San Marco JL. Validation of a French health-related quality of life instrument for adolescents: the VSP-A. Qual Life Res. 2000;9(4):393-403. doi:10.1023/A:1008957104322

14. Garrison WT, Earls F. The child behavior checklist as a screening instrument for young children. $J$ Am Acad Child Psychiatry. 1985;24 (1):76-80. doi:10.1016/S0002-7138(09)60413-1

15. Achembach TM, Rescorla LA. Manual for the ASEBA school-age forms \& profiles. Burlington, VT: University of Vermont. Research Centre for Children, Youth \& Families; 2001:4.

16. Goodman R. The Strengths and Difficulties Questionnaire: a research note. J Child Psychol Psychiatry. 1997;38(5):581-586. doi:10.1111/ j.1469-7610.1997.tb01545.x

17. Landgraf JM, Maunsell E, Speechley KN, et al. Canadian-French, German and UK versions of the Child Health Questionnaire: methodology and preliminary item scaling results. Qual Life Res. 1998;7 (5):433-445. doi:10.1023/A:1008810004694

18. Chaplin JE, Szakács A, Hallböök T, Darin N. The development of a health-related quality-of-life instrument for young people with narcolepsy: nARQoL-21. Health Qual Life Outcomes. 2017;15(1):135. doi:10.1186/s12955-017-0707-8

19. Szakács A, Chaplin JE, Tideman P, et al. A population-based and case-controlled study of children and adolescents with narcolepsy: health-related quality of life, adaptive behavior and parental stress. Eur J Paediatr Neurol. 2019;23(2):288-295. doi:10.1016/j. ejpn.2019.01.004

20. Wild D, Grove A, Martin M, et al. Principles of good practice for the translation and cultural adaptation process for patient-reported outcomes (PRO) measures: report of the ISPOR task force for translation and cultural adaptation. Value Health. 2005;8(2):94-104. doi:10.1111/j.1524-4733.2005.04054.x

21. Guo JY, Li Z. The process of introducing the scale and evaluation criteria. Chin J Nurs. 2012;47(3):283-285. doi:10.3761/j.issn.02541769.2012.03.039

22. Melendres MC, Lutz JM, Rubin ED, Marcus CL. Daytime sleepiness and hyperactivity in children with suspected sleep-disordered breathing. Pediatrics. 2004;114(3):768-775. doi:10.1542/peds.20040730

23. Chan EY, Ng DK, Chan CH, et al. Modified Epworth Sleepiness Scale in Chinese children with obstructive sleep apnea: a retrospective study. Sleep Breath. 2009;13(1):59-63. doi:10.1007/ s11325-008-0205-7

24. Terwee CB, Bot SD, de Boer MR, et al. Quality criteria were proposed for measurement properties of health status questionnaires. J Clin Epidemiol. 2007;60(1):34-42. doi:10.1016/j. jclinepi.2006.03.012

25. Hooper D, Coughlan J, Mullen MR. Structural equation modelling: guidelines for determining model fit. Electron J Bus Res Methods. 2008;6(1):141-146.

26. McConnell S, Kolopack P, Davis AM. The Western Ontario and McMaster Universities Osteoarthritis Index (WOMAC): a review of its utility and measurement properties. Arthritis Rheum. 2001;45 (5):453-461. doi:10.1002/1529-0131(200110)45:5<453::AIDART365>3.0.CO;2-W

27. Ganz PA. Impact of quality of life outcomes on clinical practice. Oncology. 1995;9(11 Suppl):61-65.

28. Zhang J, Han F. Sleepiness in narcolepsy. Sleep Med Clin. 2017;12 (3):323-330. doi:10.1016/j.jsmc.2017.03.008

29. Ong JC, Fox RS, Brower RF, Mazurek S, Moore C. How does narcolepsy impact health-related quality of life? A mixed-methods study. Behav Sleep Med. 2021;19(2):145-158. doi:10.1080/ 15402002.2020.1715411 


\section{Publish your work in this journal}

Nature and Science of Sleep is an international, peer-reviewed, open access journal covering all aspects of sleep science and sleep medicine, including the neurophysiology and functions of sleep, the genetics of sleep, sleep and society, biological rhythms, dreaming, sleep disorders and therapy, and strategies to optimize healthy sleep.
The manuscript management system is completely online and includes a very quick and fair peer-review system, which is all easy to use. Visit http://www.dovepress.com/testimonials.php to read real quotes from published authors. 